\title{
A measure of innovation performance: the Innovation Patent Index
}

\author{
Linda Ponta, Gloria Puliga and Raffaella Manzini \\ LIUC - Università Cattaneo, Castellanza, Italy
}

A measure of innovation performance

\begin{abstract}
Purpose - The measure of companies' Innovation Performance is fundamental for enhancing the value and decision-making processes of firms. The purpose of this paper is to present a new measure of Innovation Performance, called Innovation Patent Index (IPI), which makes it possible to quantitatively summarize different aspects of firms' innovation.

Design/methodology/approach - In order to define the IPI, a secondary source, i.e. patent data, has been used. The five dimensions of IPI, i.e. efficiency, time, diversification, quality and internationalization have been defined both analyzing the literature and applying three different machine learning algorithms (regularized least squares, deep neural networks and decision trees), considering patent forward citations as a proxy of the innovation performance.

Findings - Results show that the IPI index is a very useful tool, simple to use and very promptly. In fact, it is possible to get important results without making time consuming analysis with primary sources. It is a tool that can be used by managers, businessmen, policymakers, organizations, patent experts and financiers to evaluate and plan future activities, to enhance the innovation capability, to find financing and to support and improve innovation.

Research limitations/implications - Patent data are not widely used in all the sectors. Moreover, the pure number of forward citations is not the only forward looking indicator suggested by the literature.

Originality/value - The demand for a useable Innovation Performance tool, as well as the lack of tools able to grasp different aspects of the innovation, highlight the need to develop new instruments. In fact, although previous studies provide several measures of Innovation Performance, these are often difficult for managers to use, do not appreciate different aspects of the innovation and are not forward looking.
\end{abstract}

Keywords Innovation patent index, Innovation performance, Measure, Patents

Paper type Research paper

\section{Introduction}

Performance measurement is fundamental for enhancing the value of companies and improving the decision-making process. Thanks to a performance measurement system, based on sets of indicators (see for details Dziallas and Blind, 2019), people can be motivated, learning can be stimulated and coordination and communication can be improved (Govindarajan and Govindarajan, 1993; Schumann et al., 1995; Kerssens-van Drongelen and Bilderbeek, 1999). In the few last years, the innovation process has become more and more complex, expensive and risky (Dziallas and Blind, 2019). The technological and competitive environments are changing dramatically and markets becoming dynamic and turbulent. The content of technological knowledge has increased within products and processes, knowledge comes out from the confluence of separate disciplines and stakeholders, and the life cycle is shortening.

(C) Linda Ponta, Gloria Puliga and Raffaella Manzini. Published by Emerald Publishing Limited. This article is published under the Creative Commons Attribution (CC BY 4.0) licence. Anyone may reproduce, distribute, translate and create derivative works of this article (for both commercial and noncommercial purposes), subject to full attribution to the original publication and authors. The full terms of this licence may be seen at http://creativecommons.org/licences/by/4.0/legalcode

This work has been supported by LIUC - Università Cattaneo under the grant "Observatory IPcube". Federico Visconti is gratefully thanked for his useful suggestions and discussions.
Received 3 May 2020 Revised 23 September 2020 5 January 2021

Accepted 11 February 2021 (1)

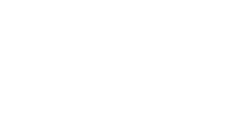

(1)


$\mathrm{MD}$

59,13

In this context, innovation performance measurement is extremely important for both firms' managers and policymakers. From a managerial point of view, new performance measurement systems are needed to efficiently manage innovation. Indeed, innovation is one of the main drivers of productivity performance (Cainelli et al., 2005; Love and Roper, 2015). In addition, firms who can show themselves to be owners of good innovations may be better able to raise funds from investors. From the policymakers point of view, timely, accurate, clear and reliable indicators are needed to set directions and rules to stimulate a fruitful innovation environment, to select industrial sectors requiring special attention, to evaluate the proposals of different applicants for innovation projects and to assess the progress of the initiatives funded (Dziallas and Blind, 2019).

So far, several indicators have been proposed to evaluate innovation performance and its impact on company productivity (see for a complete review Dziallas and Blind (2019) and Chiesa et al. (2008)).

The main source for measuring innovation performance is primary data, i.e. interviews with managers or surveys. However, primary sources are based on small sets of data (Kitsios and Kamariotou, 2016) because of difficulties in terms of firm reachability, costs, insufficient data quality, not to mention, companies' willingness to answer sensitive questions about their processes (Walsh, 1994). In addition, when based on a Likert scale [1], they are affected by respondents' subjectivity. Often, in order to avoid subjectivity, dichotomous questions are proposed, but they do not allow the nuances of the phenomena under investigation to be captured; see for example the Community Innovation Survey (CIS) [2]. In fact, studies on binary variables (yes/no measures) are clear in terms of low bias and are also efficient, but they miss some of the complexity involved in the innovation process (De Jong and Vermeulen, 2006).

In order to overcome the above mentioned problems, other measures based on secondary data, such as patents or publications have been proposed (Garg and Padhi, 1998; Burrus et al., 2018). Patents provide rich qualitative and quantitative information on technological change (Scherer, 1992); in fact the criteria behind patentability of any invention are its utility (industrial application), novelty and non-obviousness (inventive step) (Encaoua et al., 2006). Patents are collected in free databases after being checked and verified by specialists. The availability of online patent databases means that patents are a simple and immediate source to measure innovation performance both for academic and industrial researchers. So far, many innovation measures based on patent data have been proposed in the literature Dziallas and Blind (2019). However, in opposition to the literature that suggests a multidimensional approach, the innovation measures based on patents are usually related only to a specific patent feature such as the number of patents issued by a firm or the number of patents forward citations. It is worth remembering that the patents forward citations are the citations received by a patent from the time of its issue. Even if the number of patents issued by a firm or the number of patents forward citations are two of the main proxies of innovation performance (Carayannis and Provance, 2008), measures based only on a specific patent feature, are restrictive, not promptly to be used and allow only an ex post evaluation. As the issue for academics, managers and policymakers is to use timely, concrete, flexible, adaptable and measurable indicators to evaluate the innovation process and its impacts on the productivity of a company (e.g., Becheikh et al., 2006; Dewangan and Godse, 2014), the existing measures present limitations from both the managerial and policy maker point of view.

Thus, in this scenario, the aim of the paper is to define a multidimensional, promptly and simple to use innovation measure based on patent data, which is richer than the number of patents and more promptly than the number of forward citations, in order to overcome the limits of existing measures. Thus, the main research question of this paper is to define a new innovation measure, that will be called Innovation Patent Index (IPI), based on secondary 
data, i.e., the patent database, that attempts to enrich the classical innovation measures, considering not only the number of patents but also other patent information identified using different machine learning algorithms. It is worth remembering that the machine learning approach is a very useful tool because it makes it possible to manage huge amounts of data and to capture the complex nonlinear relationships among the data features. In particular, in this paper, as described in Ponta et al. (2020a, b), three different algorithms, i.e., regularized least squares (RLS), deep neural networks (DNNs) and decision trees (DTs), have been employed to identify the most relevant patent features, in predicting innovation performance. Finally, the identified features have been aggregated in dimensions in order to create a userfriendly instrument, i.e. the Innovation Patent Index (IPI), for academics, managers and policymakers. Figure 1 shows the goal of the paper and the process of analysis.

\section{Literature review}

\subsection{Innovation performance and its measures}

Innovation is one of the main processes of a firm organization and its management and measurement should be defined as a structured process (Janssen et al., 2011). Innovation is one of the determinants of firm performance and results (Hou et al.,2019) and the promotion of an innovation culture is of fundamental importance (Hanifah et al., 2019). For these reasons, innovation performance and its antecedents have been studied in several different contexts, from multinational and subsidiaries (Nuruzzaman et al., 2019; Gaur et al., 2019; Bahl et al., 2020) to SMEs (Hanifah et al., 2019; Saunila, 2016). The definition of appropriate innovation measures contributes to the understanding of the innovation itself, gives the opportunity to enhance the performance and increases the innovation culture (Saunila, 2016).

The measurement systems should act as a managerial tool that supports R\&D decisions, providing information about strengths and weaknesses of companies' innovation activities. In addition, they should act also as monitoring and evaluation tools for institutional bodies, who can "see" the behavior of firms or groups of firms. Moreover, it should be a
A measure of innovation performance

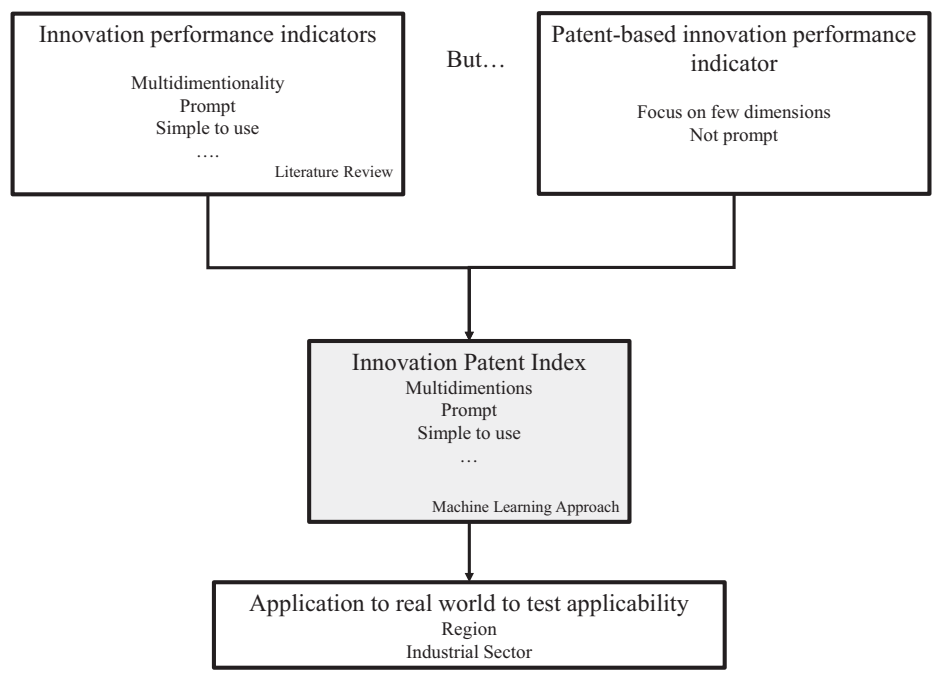

Source(s): Authors' conceptualization

Figure 1. Research goal and process of analysis 
$\mathrm{MD}$

59,13

benchmarking tool, allowing the company to compare its own results with other companies or also contexts (Lazzarotti et al., 2011).

Over the years the measurement of innovation has raised different issues. Disparities emerging between the studies have failed to develop a unique understanding of innovative performance systems and a common set of indicators at the organization level. A review of more recent studies provides some principles to develop an appropriate measurement system (Dewangan and Godse, 2014). These principles claim that performance measurement systems should be focused also on firm level, should be multi-dimensional, process based, meet stakeholders' goals, propose a cause and effect relationships between measures, as well as being promptly and easy to implement and use (Dewangan and Godse, 2014; Scalera et al., 2014; Lazzarotti et al., 2011). The measurement of innovation performance has often been analyzed at a project or technological level. The analysis at the firm level has been less examined (Carayannis and Provance, 2008). Project-level studies provide a shaded understanding of the innovation mechanisms; this limits the controls that managers have to make decisions in uncertain and dynamic environments. Multiple or composite measures should be preferred in determining a firm's innovation level and a multidimensional view of performance should be provided. Composite indicators allow the multiple determinants of innovation performance to be captured. The assumption behind a multiple-composite indicator is that superior innovation occurs when firms maximize all dimensions of the innovation activity (Lazzarotti et al., 2011; Tohumcu and Karasakal, 2010; Ojanen and Vuola, 2006). The advantage of this approach is that it provides a more informative measure of the innovation performance level of a company. Indeed, each indicator has a different meaning. When one specific indicator diverges from the others, it can be analyzed separately as it contributes to the "innovative performance." The indicators should include throughput measures of innovation (Hagedoorn and Cloodt, 2003). Considering process performance is important in order to focus on continuous improvement and to facilitate the competitive benchmarking and identification of potential problems or inefficiencies. Stakeholder goals should be addressed and merged to take into account those of multiple stakeholders. The performance measurement should be built on the basis of cause and effect linkages between the measures. It should address past and probable future performance by including both leading and lagging indicators. This allows managers to evaluate the value of different activities and relate them to specific results. An effective performance measurement should include indicators that can be measured promptly. In a turbulent environment, managers should take action in advance with respect to their competitors (Liu et al., 2015; Soosay and Chapman, 2006). If the proposed indicators can be evaluated only after a lapse of time or if a long time is needed to collect these data, the information about the performance may no longer be useful. The scheme should be easy for the different firm areas to implement and use.

\subsection{Innovation performance and their measures with patents}

In the literature, many researchers present patents as a source for innovation measurement (Scherer, 1965; Pakes and Griliches, 1980; Griliches, 1990; Jaffe and Palmer, 1997; De Rassenfosse et al., 2013; Acs et al., 2002; Lanjouw and Schankerman, 2004; Nagaoka et al., 2010). Most scientific works investigate the relationship between patent counts and innovation performance, considering patents as an R\&D output. In Svensson (2015), the number of patents per capita is used to estimate the rank of sectors and countries in terms of technology intensity or innovation. De Rassenfosse et al. (2013) present a new methodology to assess innovation performance by counting priority patent applications filed by a country's inventors regardless of the patent office. Hagedoorn and Cloodt (2003) analyze innovation performance of countries proposing two ratios: inventive performance and invention productive performance based on the total patent count and R\&D indicators. Dechezleprêtre 
and Martin (2010) compare both relative levels and trends in clean innovation activity between different countries taking patent counts as an innovation measure to portray a picture of where UK is standing in terms of climate change mitigation innovation. Thus, patent count is still considered as a satisfactory measure for innovation. However, De Rassenfosse et al. (2013) outline some major drawbacks of patent counts: the value distribution of patents is skewed as many patents do not have industrial applications; many inventions are not patented and many inventions are not patentable when other means of protection, i.e. trade secrecy, lead-time on the market or reputation are more useful; counting patents has become difficult due to the differences in patent regulations across countries (Papageorgiadis and Sofka, 2020). The OECD Patent manual of 1994 also underlines that patent statistics should be interpreted with caution due to the variations in propensity to patent across time, firms, industries and countries. These limitations have led researchers to consider other indicators along with patent counts such as forward and backward citations, patent family size, patent renewal, opposition and litigation information and also build patent related indexes (Papageorgiadis and Sofka, 2020; Datta et al., 2015). In particular, patent forward citations appear to be one of the most widely used indicators (Hall et al., 2005). They are the citations received by a given patent from other patents. For that reason, they are partially available only after a substantial time since the granting. Forward citations are particular in that they to grasp not only the technological value of an innovation and its originality, but also its relevance toward the market (Aristodemou and Tietze, 2018). Forward citations may be a measure to understand emerging technologies or to evaluate the economic value of a technology and the innovation capacity of a company (Hall et al., 2005). Moreover, Mueller (2015) states that patent information provides more indicators than just the sheer number of patents over time. For example, the origin of inventor the can represent an excellency of the higher education system when the population of the country is taken into account, or statistical evaluation of jurisdictions in which patent family members were granted can give information about the priority markets for the country considered. Finally, Lanjouw and Schankerman (2004) suggest measuring innovation with a composite index of patent quality using different indicators of patents in order to reduce a measured variance in quality.

The main purpose of this paper is to define an Innovation Patent Index based on secondary data that can overcome the limitation of the indicators based only on one feature of patents, such as the number of patents and also be able to appreciate the value the market gives to the patented technology.

\section{Methodology}

In order to build an innovation performance indicator based on secondary data, i.e. the patents database, that can overcome the serious limitations of existing innovation indicator underlined in Section 1, first of all the relevant patent features have been extracted from all the information included in the patents database. In particular, starting from all the data in the patent database, the 24 patent features, reported in Table 1 were identified. As said above in section 1, the paper aims to build a multidimensional, promptly and simple to use measure of the innovation performance. Thus, starting from the 24 patents features identified we wanted to build an indicator that considers all this information. To do this, the number of forward citations, i.e. the number of citations received by a patent, was considered as a proxy of the innovation performance, whereas the other features were considered as potentially predictive of the innovation performance (Narin et al., 1984; Ponta et al., 2020a, b). In this way we are able to create a simple index that is multidimensional because it considers all the information inside the patent database, is timely because it considers all the features that are directly available when the patent is issued and is simple because it considers only a reduced

A measure of innovation performance 
MD

59,13

\begin{tabular}{ll}
\hline Description & Definition \\
\hline Date of the first application for the family & $\begin{array}{l}\text { Date of the origin of the novelty } \\
\text { Date of application of the patents }\end{array}$ \\
$\begin{array}{l}\text { Timen the company presents a novelty } \\
\text { towe world, receives the approval from } \\
\text { authorities and expires }\end{array}$
\end{tabular}

Usage

Date of grant

Date of expire

Technical concepts

Technological domain

IPC classification with 9 digits

First country of application

Backward citations

Independent claims

Dependent claims

Number of assignees

Technical concepts: knowledge owned by the company since they report the core information content about technology Choi and Hwang (2014)

Technical domains and technological classes based on The Ipc: "Breadth" and the "Scope" of a patent, identifying where the company invests Moaniba et al. (2018)

Place where the knowledge arises Mahnken and Moehrle (2018)

Knowledge owned within the company that is recombined in order to have a novelty step Harhoff et al. (2003), Hall et al. (2007)

Breadth of a patent, it reveals information about its inventive step (non-obviousness). the claims are the expression of the value in stock of the company Bessen (2008), Reitzig (2004)

Strategy adopted by the company to create a network for developing technology Belderbos et al. (2014)

Months between the publication date of the youngest and the oldest patent of the family

Number of months between the date of publication of youngest and the oldest patent of the patent family: period needed by the maturation process of innovations to reach a higher level of maturity Dechezleprêtre $e t a l$. (2017)

Number of words in the document

Features related to the patent structure (for example the number of words in the document or in the abstract): ability of company to explain the knowledge owned inside Reitzig (2004)

Number of technical terms in the abstract Number of words in the description

Number of authorities

Number of figures

Number of priorities

Market of the technologies and the countries where the technology must be protected (Harhoff et al., 2003)

Size of the family

Table 1.

Number of patents that share the same novelty and belong to an unique family

Number of citing patents

Predictive

Predictive

Features' description of Forward citations patents

number of features. In order to identify which features are predictive of the forward citations the machine learning approach was chosen. Despite their "dark side" (Siau and Wang, 2020) in terms of ethics, machine learning algorithms let to manage a huge amount of data such as the one embodied in patents and to discover linear and not linear relations (Tu, 1996). 


\subsection{Data and patent features}

The data analyzed in building the innovation performance index, are the patents collected from 1st January 2005 to 31st December 2018 for 32 states, i.e., the 28 members states of the EU plus Iceland, Liechtenstein, Norway and Switzerland. A total of about 8 million patents were considered. In particular, the analysis was performed for each country considering where firms have the registered office or where inventors have their residence. The data source chosen was The Orbit Intelligence database, provided by Questel [3] one of the world's leading intellectual property management companies.

\subsection{Artificial intelligence approaches}

The problem of identifying which patents features are relevant in predicting innovation performance, approximated with the forward citations, can be mapped into a conventional regression framework. The main steps are: first, the identification of the relation $\Re$ between the input $\mathscr{X}$, namely the features described in Table 1 , and an output space $\mathscr{Y} \subseteq \mathbb{R}$, namely the number of forward patent citations (Shalev-Shwartz and Ben-David, 2014); second, the discovery of the most influencing factors in the input space for predicting the correct associated element in the output space (Altmann et al., 2010); third, understanding how the influencing factors in the input space influence the associated value in the output space. The goal is to identify a model/function $\mathfrak{M}: \mathscr{X} \rightarrow \mathscr{Y}$, for approximating $\mathfrak{R}$, through a learning algorithm $\mathscr{A} \mathscr{H}$ characterized by a particular set of hyperparameters $\mathscr{H}$. The accuracy of approximation $\mathfrak{M}$ in representing the unknown relation $\mathfrak{R}$ is measured with the Mean Absolute Percentage Error (MAPE) (Cincotti et al., 2014). The interpretability, namely the possibility to understand how it behaves, ranks the features based on their effect on the learned model (Guyon and Elisseeff, 2003; Altmann et al., 2010). Three different machine learning algorithms have been implemented to determine the most important features, i.e., RLS, DNNs and DTs.

These algorithms are fast to train, powerful in managing non-linear relations, easy to exploit in practice and interpretable (Lulli et al., 2018). For details in solving the problem described above with RLS, DNNs and DT algorithms, see Ponta et al. (2020a, b)

\subsection{Machine learning results}

The results of the three machine learning algorithms used to predict forward citations show that the most relevant features identified are the technological classes ( 4 and 7 digit), based on the IPC, the technological domain and the number of backward citations (Ponta et al., 2020a, b). Moreover, the size of the patents family, representing the geographical extension of the patent, is a valuable feature for estimating the market value of a patent, as suggested by Harhoff $e t a l$. (2003). Another important feature is represented by the time-related determinant of months between the date of publication of the youngest and the oldest patent of the family. This feature provides information on how companies invest in innovation over-time and build their capabilities (Dechezleprêtre et al., 2017).

It is worth noting that all the three algorithms extracted the same patents features as important in predicting the forward citations, i.e. innovation performance. See Ponta et al. (2020a, b) for further details.

\section{Innovation indicators and Innovation Patent Index}

Starting from both the literature and the results described in Section 3.3, an index composed of the simplest and most common measures of innovation used in literature, i.e. the number of patents and of the patents' features identified above was defined. The index is formed of five different indicators: (a) Efficiency: the normalized number of patents (b) Internationalization: the number of extensions (c) Diversification: the number of IPC classes (d) Quality: the number of backward citations (e) Time: the number of months between the publication date of the youngest and the oldest patent of the family. The efficiency indicator makes reference to

A measure of innovation performance 
$\mathrm{MD}$

59,13

the literature, whereas the others make reference to the main patents' features, empirically derived by the machine learning algorithms, i.e. RLS, DNNs and DTs, as described in Section 3.3. In fact, machine learning is a well suited tool to extract significant relevant information from complex, nonlinear and noisy data (Tkáč and Verner, 2016). For this reason, in recent years and, thanks to the large availability of data, authors have applied machine learning algorithms to various problems such as financial topics, for example, credit scoring, financial analysis, or stock performance prediction, and costs monitoring and sales analysis (Tkác and Verner, 2016). Recently, the use of these tools has been extended to the field of management in order to support business research and managers in their decision making process. Table 2 summarizes all the patent indicators, derived by the machine learning algorithms or by the literature, that form the IPI index.

Before defining each indicator, let's define the main characteristics of patent $p$

(1) $e_{p}$ number of extensions of patent $p$;

(2) $b_{p}$ number of backward citation of patent $p$;

(3) $c_{p}$ number of classes patent $p$;

(4) $m_{p}$ number of months between the publication date of the youngest and the oldest patent of the family.

\subsection{Efficiency}

The efficiency indicator is defined as the normalized number of patents. Given a company $i$, its efficiency $E_{i, t}$ at time $t$ is given by the following formula:

$$
E_{i, t}=\frac{\sum_{t=0}^{T} n_{i}(t)}{N_{i}}
$$

where $N_{i}$ is the total number of employees of firm $i$. In the case of a region or a country $i$, the efficiency is evaluated according to Eq. (1), where $n_{i}(t)$ is the number of patents published in region $i$ at time $t$ and $N_{i}$ is the total number of employees of region or country $i$.

\subsection{Diversification}

The diversification indicator is defined as the number of IPC classes (4 digit) of each patent. Given a company $i$, the diversification $D_{i, t}$ is given by:

$$
D_{i, t}=\frac{\sum_{t=0}^{T} \sum_{n=1}^{n_{i}(t)} c_{p, i}(t)}{\sum_{t=0}^{T} n_{i}(t)}
$$

This indicator is important because it has been proven that small incremental innovations do not enhance firms innovation performance, see for example (Moaniba et al., 2018), whereas the kind and not the number of technical domains selected by the company are significant.

\begin{tabular}{llll}
\hline Symbol & Description & Definition & Source \\
\hline E & Efficiency & Normalized number of patents & $\begin{array}{l}\text { Scientific } \\
\text { literature }\end{array}$ \\
M & Time & $\begin{array}{l}\text { Number of months between the publication date of the } \\
\text { Machine }\end{array}$ \\
D & Diversification & $\begin{array}{l}\text { Noumgest and the oldest patent of the family } \\
\text { learning results }\end{array}$ & \\
Q & Quality & Number of backward citations & \\
I & Internationalization & Number of extensions & \\
\hline
\end{tabular}

Table 2. 


\subsection{Quality}

The quality indicator is defined as the number of backward citations. Given a company $i$, the quality indicator is given by:

$$
Q_{i, t}=\frac{\sum_{t=0}^{T} \sum_{n=1}^{n_{i}(t)} b_{p, i}(t)}{\sum_{t=0}^{T} n_{i}(t)}
$$

Backward citations play a main role in predicting IC, so companies must be aware that their capacity to absorb previous knowledge and make use of it will strongly affect future innovation and the ability to be competitive (Harhoff et al., 2003; Hall et al., 2007).

\subsection{Internationalization}

The internationalization indicator is defined as the number of geographical extensions of a patent. Given a company $i$, the internationalization $I_{i, t}$ indicator is given by:

$$
I_{i, t}=\frac{\sum_{t=0}^{T} \sum_{n=1}^{n_{i}(t)} e_{p, i}(t)}{\sum_{t=0}^{T} n_{i}(t)}
$$

\subsection{Time}

The time indicator is defined as the road chosen by the firm to patent. Given a company $i$, the time dimension $R_{i, t}$ is given by:

$$
M_{i, t}=\frac{\sum_{t=0}^{T} \sum_{n=1}^{n_{i}(t)} m_{p, i}(t)}{\sum_{t=0}^{T} n_{i}(t)}
$$

\subsection{Innovation Patent Index}

Given the five previously defined indicators, an index that summarizes the five values is defined. The Innovation Patent Index (IPI) is defined by five dimensions, which are the five indicators just described: efficiency, time, diversification, quality and internationalization, as shown in Figure 2. The IPI is evaluated as a weighted average of the normalized five indicators, in formula,

$$
I P I_{i, t}=\alpha_{1} E_{i, t}+\alpha_{2} D_{i, t}+\alpha_{3} Q_{i, t}+\alpha_{4} I_{i, t}+\alpha_{5} M_{i, t}
$$

where $\alpha_{1}, \alpha_{2}, \alpha_{3}, \alpha_{4}$ and $\alpha_{5}$ are real numbers. So far, the $\alpha$ coefficients are positive and all equal. Thus, IPI is a real number that ranges between 0 and 10 . Moreover, it is important to underline that in order to evaluate the IPI for a firm or a region it is necessary to define the period of observation $T$, i.e. the number of years.

\section{Application to real world}

In order to show how the IPI, defined in Section 4, can be used, this section shows how it has been applied in two cases. In case (a) IPI was employed to evaluate the innovation performance of the Lombardy region and of its provinces, whereas in case (b) IPI was used to measure the innovation performance of the firms belonging to the AMAPLAST [4] association. AMAPLAST is the association of the most important Italian firms working in the plastic materials sector. The data source used in these analyses is The Orbit Intelligence database [5]. All the patents published by inventors with residence in Lombardy or by firms with registered office in Lombardy, or belonging to the AMAPLAST association were 
$\mathrm{MD}$

59,13

82

Figure 2.

The five dimensions of IPI

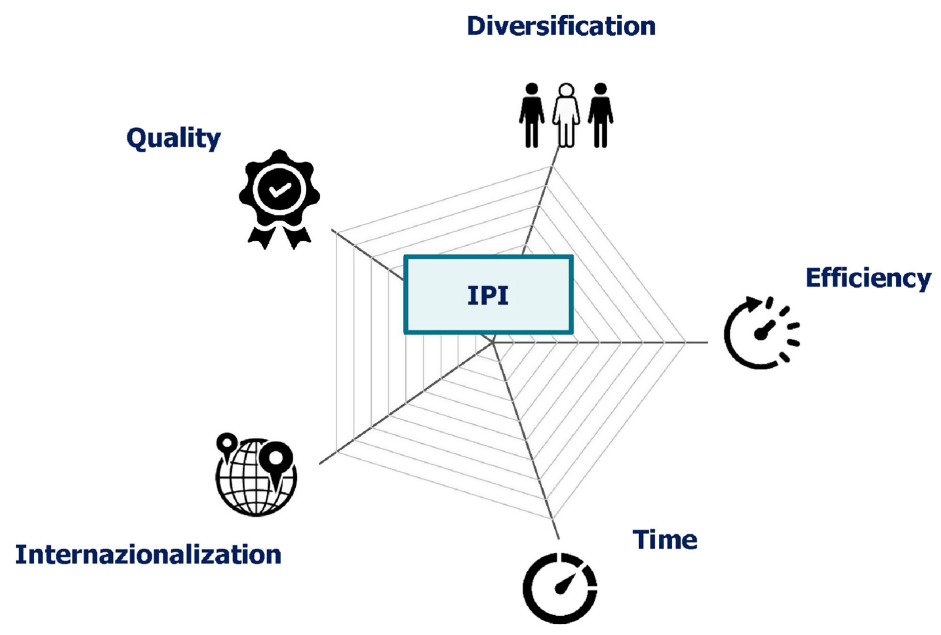

collected over the period, 2000 to 2017. For each patent, the list of all considered features is shown in Table 1.

\subsection{IPI and Lombardy region (case (a))}

Figure 3 shows the IPI measure in case (a), the Lombardy region in the period 2012-2017. The different colors on the map represent the classification. The province in dark blue represents the one with the largest IPI, and thus the most innovative province, whereas the province in light blue represents the one with the smallest IPI. All the shades of blue represent the IPI classification.

As said in Section 3.3 IPI is defined by five indicators, so it is possible to investigate in more detail the results shown in Figure 3, to give information to managers about the reasons for the classification. Thus, an analysis of the five IPI dimensions was performed. Figure 4 shows the IPI dimensions in the period after the economic crisis for three Lombardy provinces, Varese, Milan and Lodi. The same analysis was performed for all the provinces and the results are shown in Appendix. The green line represents the province and the pink line the region. It is possible to observe that provinces that are ranked as most innovative by the IPI have very different IPI indicators. For example, the province of Milan has a very high efficiency score whereas Lodi, a very small province of Lombardy, has a very high quality and time score. The province of Varese, that is ranked in the upper half of the classification, is only higher than the other provinces in terms of diversification. Moreover, it is possible to investigate more each dimension in more detail considering its evolution during the time period of analysis. Figure 5 shows the five dimensions of IPI for the provinces of Varese, Milan and Lodi for each year and thus their evolution over time. The analysis of all the provinces of the Lombardy region is presented in Appendix. In particular, it is possible to observe that, in the time range considered, in Figure 5a the diversification is the most important dimension in the IPI evaluation, in Figure 5b the efficiency and in Figure $5 c$ time and quality. The analysis of each dimension of IPI for each year gives further information about the innovation trend of the companies belonging to the same province. For companies this information has very important results because they have information about what to improve in order to increase the innovation performance.Moreover, it is possible to investigate the results in the period 2012-2017 (post crisis) comparing different time ranges. Figure 6 shows the IPI's dimensions of the Lombardy region and of the three provinces 


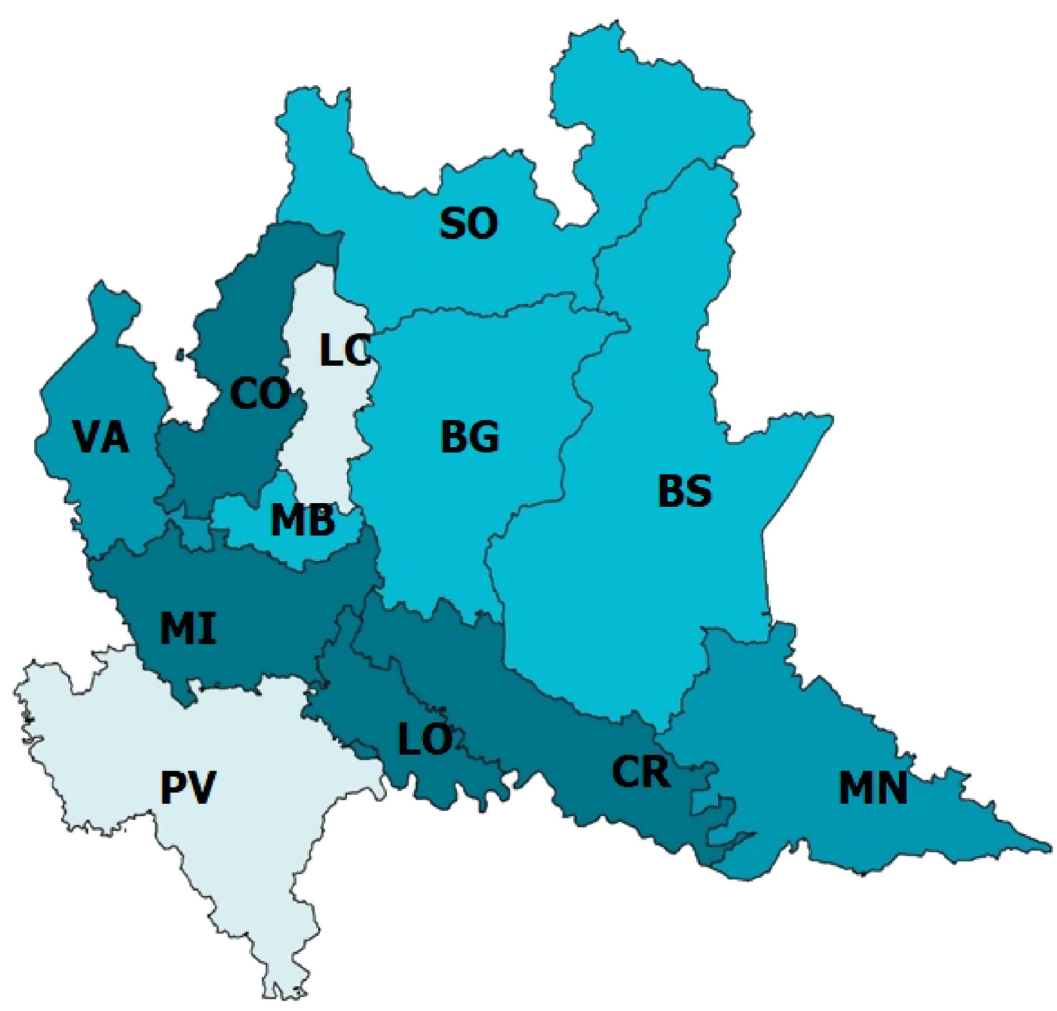

A measure of innovation performance

83

Figure 3.

IPI rank

Varese, Milan and Lodi in three different periods. The green line represents the dimensions before the crisis (2000-2006), the pink line during the crisis (2007-2011) and the black line after the crisis (2012-2017). Figure 6a shows that all the indicators except quality decrease after the crisis. This means that after the crisis there are fewer patents but with better quality. During the crisis, the time spent in developing the patent, i.e. the resources spent on it, seems longer than the period before the crisis.

In addition, the IPI's dimensions of each province is evaluated in different periods. Figures $6 \mathrm{~b}, 6 \mathrm{c}$, and $6 \mathrm{~d}$ show the different IPI dimensions in different time periods for the province of Varese, Milan and Lodi, respectively. Each province has its own peculiarity but also for the provinces the IPI dimensions after the crisis are smaller than the ones before the crisis. Summarizing the results of case (a), Tables 3-5 report for each province the values of the indicators and the IPI in the three periods, before, during and after crisis, respectively. For example, we can notice how the territory of Milan clearly stands out in terms of efficiency, while other territories such as Como, smaller than Milan, grow in terms of diversification and time.

\subsection{IPI and AMAPLAST (case (b))}

The IPI measure was used to measure the innovation performance of firms belonging to the AMAPLAST [6] association. For privacy reasons the paper does not report the innovation performance of each firm, but the behavior of the five indicators of IPI for small, medium and large firms. Small means that firms have less than 50 employees, medium means that firms 
MD

59,13

84
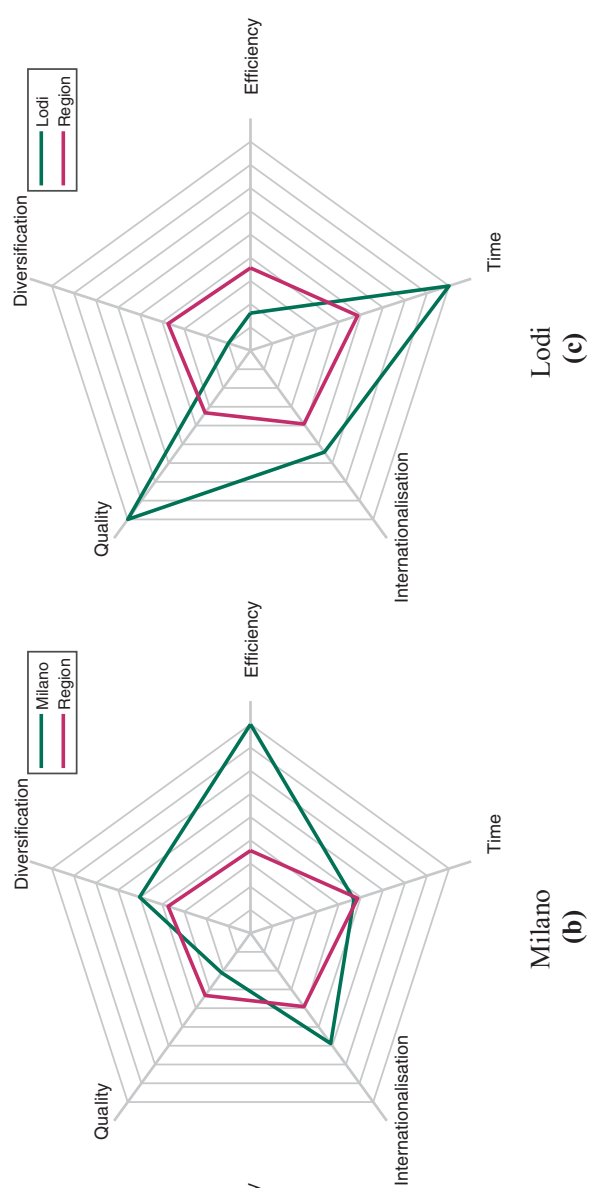

Figure 4.

IPI dimensions in the period after crisis

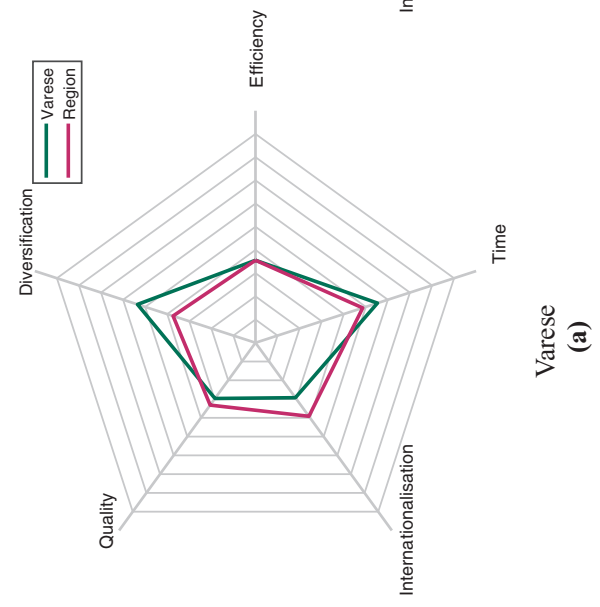




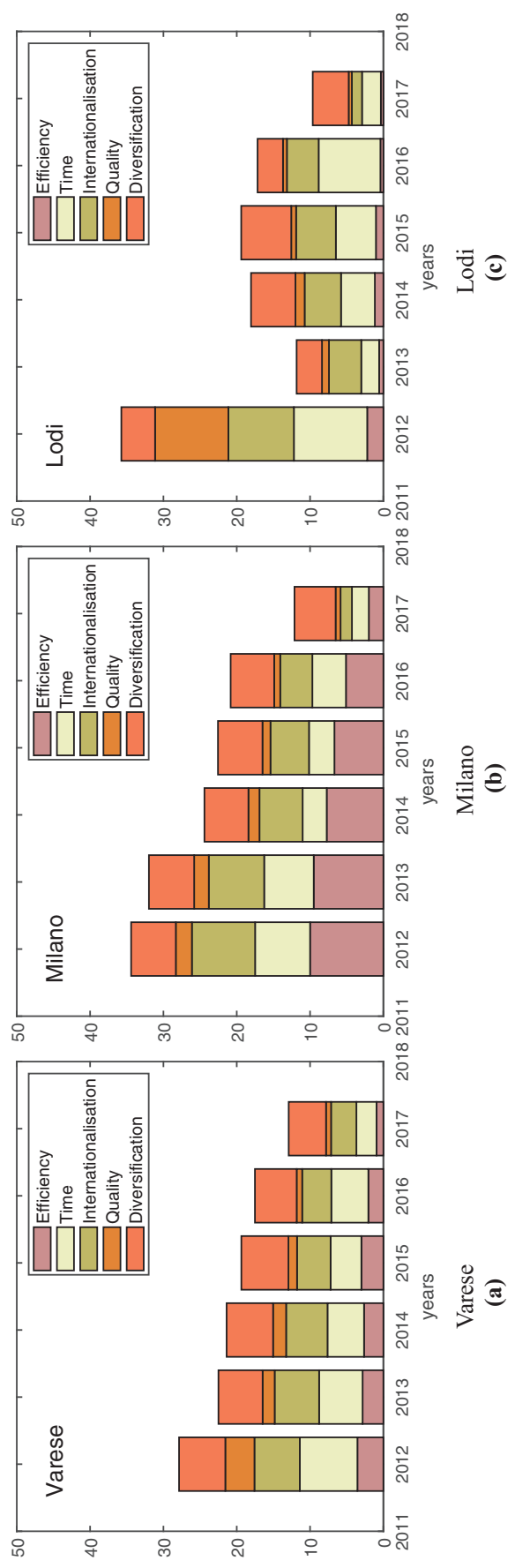

A measure of innovation performance

85

Figure 5.

IPI dimensions in the period after crisis year by year 
MD

59,13

86

Figure 6.

The green line represent the

dimensions before the crisis (2000-2006), the pink line during the crisis (2007-2011) and the black line after the crisis (2012-2017)

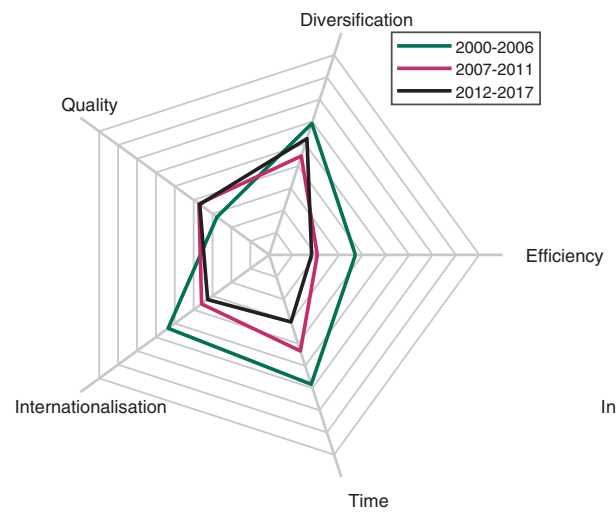

Lombardy

(a)

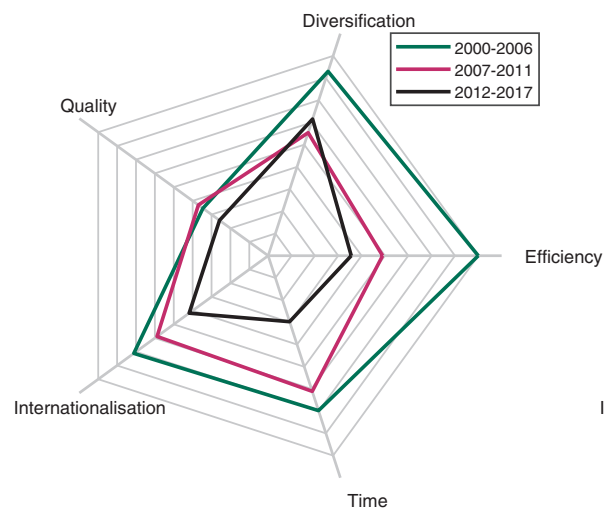

Milano

(c)

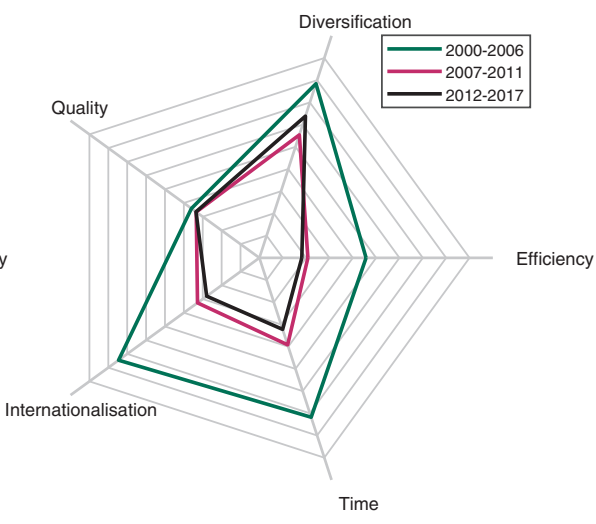

Varese

(b)

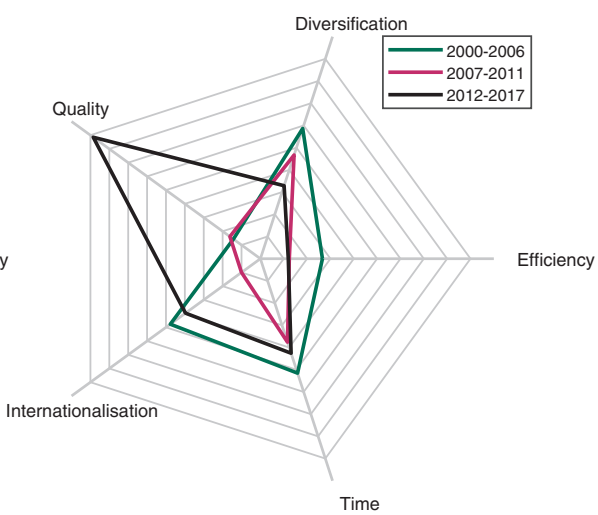

Lodi

(d)

\begin{tabular}{lrrcrrr}
\hline Provinces & Efficiency & Time & Internationalization & Quality & Diversification & IPI \\
\hline Varese & 4.462 & 7.722 & 8.072 & 3.248 & 8.555 & 6.412 \\
Bergamo & 3.322 & 4.596 & 3.541 & 1.968 & 4.206 & 3.526 \\
Milano & 10.000 & 7.469 & 7.643 & 3.070 & 9.126 & 7.462 \\
Brescia & 2.556 & 3.574 & 3.508 & 2.071 & 4.138 & 3.169 \\
Monza Brianza & 0.035 & 10.000 & 3.339 & 3.324 & 10.000 & 5.340 \\
Como & 4.656 & 7.230 & 10.000 & 3.531 & 8.417 & 6.767 \\
Pavia & 2.585 & 7.303 & 5.509 & 1.392 & 6.977 & 4.753 \\
Mantova & 3.964 & 6.176 & 6.268 & 3.033 & 6.036 & 5.095 \\
Cremona & 2.869 & 6.561 & 5.929 & 2.693 & 6.268 & 4.864 \\
Lecco & 3.584 & 4.752 & 6.083 & 1.570 & 3.973 & 3.992 \\
Sondrio & 0.299 & 1.869 & 0.677 & 0.000 & 0.000 & 0.569 \\
Lodi & 2.072 & 5.192 & 4.713 & 0.536 & 6.080 & 3.719 \\
\hline
\end{tabular}




\begin{tabular}{|c|c|c|c|c|c|c|c|}
\hline Provinces & Efficiency & Time & Internationalization & Quality & Diversification & IPI & A incasule \\
\hline Varese & 1.347 & 3.646 & 2.847 & 2.930 & 5.672 & 3.288 & performance \\
\hline Bergamo & 1.308 & 4.359 & 3.293 & 3.233 & 3.818 & 3.202 & \\
\hline Milano & 4.877 & 6.386 & 6.105 & 3.369 & 5.675 & 5.282 & \\
\hline Brescia & 1.695 & 5.398 & 5.408 & 4.281 & 1.902 & 3.737 & \\
\hline Monza Brianza & 0.090 & 4.618 & 0.438 & 2.645 & 5.612 & 2.681 & \\
\hline Como & 1.439 & 3.616 & 3.973 & 3.638 & 3.277 & 3.189 & 87 \\
\hline Pavia & 0.942 & 4.590 & 2.666 & 2.391 & 5.251 & 3.168 & \\
\hline Mantova & 1.473 & 4.940 & 6.188 & 10.000 & 2.056 & 4.931 & \\
\hline Cremona & 1.240 & 5.635 & 4.618 & 2.283 & 4.567 & 3.669 & Table 4 \\
\hline Lecco & 1.134 & 3.285 & 0.717 & 1.589 & 2.617 & 1.868 & Dimension indicators \\
\hline Sondrio & 0.083 & 0.000 & 2.426 & 3.676 & 6.748 & 2.587 & and IPI during crisis \\
\hline Lodi & 0.297 & 3.447 & 0.000 & 0.766 & 4.588 & 1.820 & 2007-2011 \\
\hline
\end{tabular}

\begin{tabular}{|c|c|c|c|c|c|c|c|}
\hline Provinces & Efficiency & Time & Internationalization & Quality & Diversification & IPI & \\
\hline Varese & 1.021 & 2.777 & 2.240 & 2.945 & 6.730 & 3.142 & \\
\hline Bergamo & 1.107 & 1.862 & 1.779 & 2.506 & 4.990 & 2.449 & \\
\hline Milano & 3.198 & 2.464 & 3.982 & 1.970 & 6.444 & 3.612 & \\
\hline Brescia & 1.370 & 2.651 & 3.031 & 2.148 & 3.712 & 2.582 & \\
\hline Monza Brianza & 0.403 & 2.948 & 3.140 & 1.102 & 5.297 & 2.578 & \\
\hline Como & 1.369 & 3.171 & 3.896 & 5.335 & 4.615 & 3.677 & \\
\hline Pavia & 0.304 & 1.088 & 1.222 & 0.701 & 6.840 & 2.031 & \\
\hline Mantova & 1.075 & 2.226 & 2.436 & 7.576 & 3.425 & 3.348 & \\
\hline Cremona & 1.153 & 3.390 & 5.818 & 2.592 & 4.679 & 3.526 & Table 5 \\
\hline Lecco & 1.016 & 1.678 & 1.104 & 1.554 & 3.961 & 1.863 & Dimension indicators \\
\hline Sondrio & 0.000 & 2.004 & 1.530 & 1.917 & 9.983 & 3.087 & and IPI after crisis \\
\hline Lodi & 0.244 & 4.071 & 3.707 & 9.815 & 2.859 & 4.139 & $2012-2017$ \\
\hline
\end{tabular}

have between 51 and 250 employees and large means that firms have more than 251 employees.

Figure 7a shows a radar plot of the five indicators composing IPI for all the companies who patent and, that belong to the AMAPLAST organization. It is worth remarking that in this graph only the 67 firms that have patented in the period of observation are plotted. In general companies have different performances if the five indicators are considered separately. There are no companies where all the indicators are very high. For example, one company may have a very high efficiency indicator but a very low diversification indicator. This shows further the importance and completeness of the IPI measure, which is able to identify the areas of weakness on which the companies must work even if the total value of the index is high. Moreover, Figure 7b shows the radar plot for AMAPLAST firms divided into small, medium and large companies. It is worth noting that IPI also gives information to sets of companies. For example, Figure 7b shows that all the three sets (small, medium and large companies) consider all the five indicators in the same way, but in more detail it is possible to observe how the set of large firms, in black, has a high quality indicator compared to the set of small and medium firms but a low efficiency indicator. Information here for managers is that large firms are more interested in having few patents but with high quality whereas for small firms, even if they give importance to the quality dimension, the efficiency, i.e. number of patents, is more important. Finally, these results show how IPI can be applied to measure the innovation performance of firms or territories, giving information both at company and territory level. 
MD

59,13

88

Figure 7.

(a) The five dimensions of IPI for all the companies belonging to AMAPLAST association that have patent in the period 2000-2017. (b)The five dimensions of IPI for the companies belonging to AMAPLAST association divided in small, medium and large

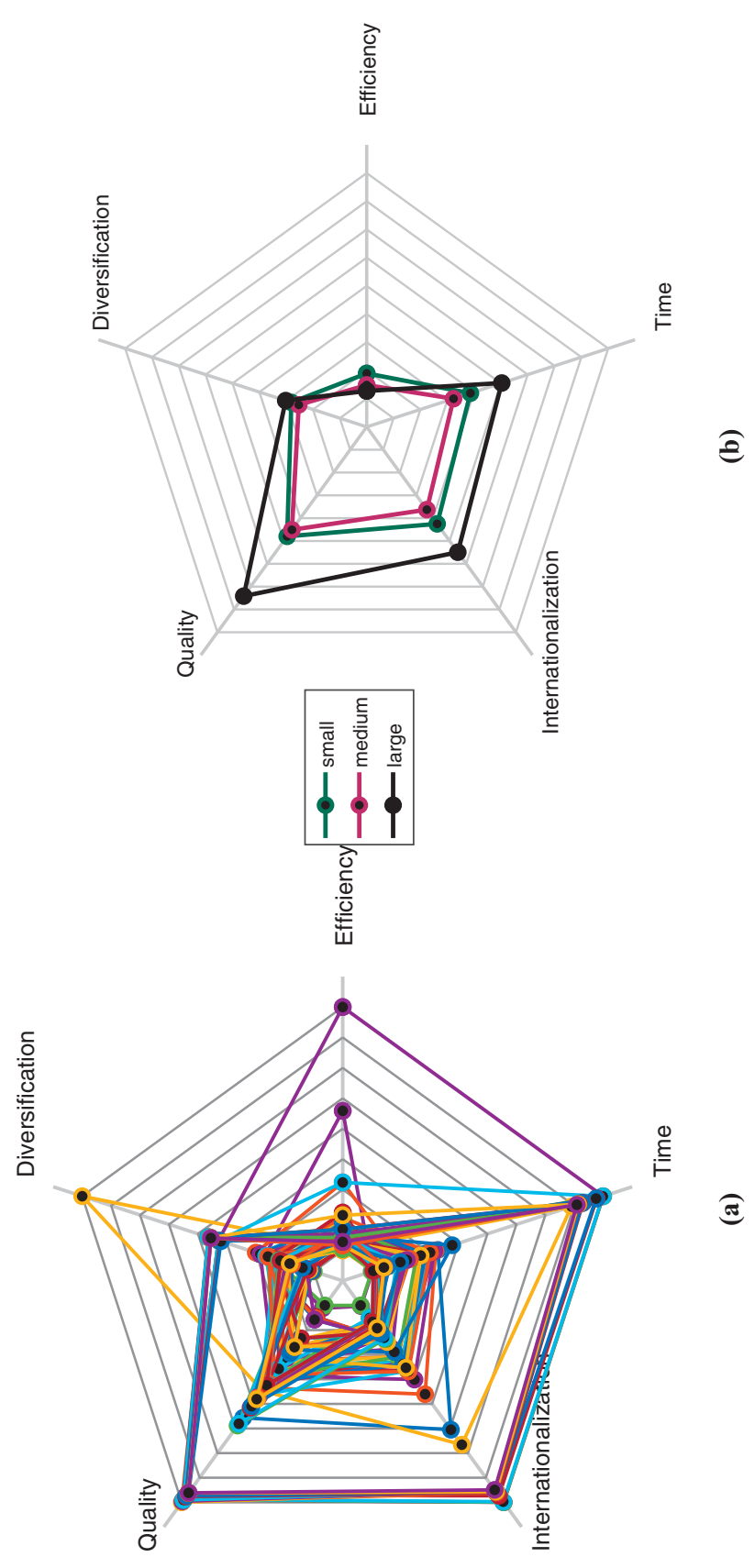


From a managerial point of view, IPI gives each firm or territory not only a rank but also information about the innovation performance profile. In fact, with the information included in the IPI dimension indicators it is possible to identify the strengths and weaknesses of innovation performance.
A measure of innovation performance

\section{Discussion}

The study shows an attempt to find an innovation performance measurement that overcomes the limits of previous studies. Over the years, researchers search for the definition of indicators to measure the company innovation process that is one of the most important determinants of the firm performance (Janssen et al., 2011; Hou et al., 2019). Nevertheless, studies are searching for developing a complete and comprehensive understanding of innovative performance systems and an appropriate set of indicators. The definition of appropriate innovation measures contributes to enhance the innovation performance, to spread the innovation culture, to benchmark companies against each other and to provide information also to institutional bodies, who can monitor and take decisions according to the performance of firms or groups of them. As suggested by Lanjouw and Schankerman (2004), the study proposes an index, i.e., the IPI. It is a novel approach and follows the main guidelines provided in the literature (Dewangan and Godse, 2014) and it is applicable in different contexts (Nuruzzaman et al., 2019; Gaur et al., 2019; Bahl et al., 2020; Hanifah et al., 2019; Saunila, 2016). The IPI is a composite indicator (Harhoff et al., 2003; Lazzarotti et al., 2011) that uses multiple information set out in patents. Moreover, it offers the possibility to use multiple indicators in prompt. Most of the previous innovation performance systems use primary sources to address the multiple perspective requirements. However, it is often difficult to collect this kind of information. Differently secondary sources data, such as those of patents are generally widely available, but they are not immediately accessible nor do they provide a multiple perspective. Most of the previous indicators to build a performance measurement system were based on the patent count or the number of patents forward citations (Dziallas and Blind, 2019). However, the use of patent count alone does not allow managers to have a multiple view. On the other hand, the use of forward citations limits the prompt use of the innovation performance measurement. Indeed, forward citations are accessible only after some time. With the identification of the patent forward citations predictors, that can be combined with the count of a firm's number of patents, the IPI is both a multiple-composite and prompt system of performance measurement. Moreover, it addresses the guidelines provided in the literature providing scholars a possible convergence on the wide range of perspectives on measurement, specifically using patent data. In particular, the IPI can be used at several different level. It is not only a project or technological level measure but, as shown in the application, it allows evaluations at project, firm and regional levels (Scalera et al., 2014; Gaur et al., 2019). Moreover, it provides a benchmark with other actors or contexts (Liu et al., 2015; Soosay and Chapman, 2006). The indicators should include throughput measures of innovation (Hagedoorn and Cloodt, 2003). It makes possible to address different perspectives and multiple stakeholder's goals, for example including learning aspects (measured with the backward citations), marketing aspects (measured with the internationalization citations). The scheme is also easy to implement and use because it only the extraction of patent information and the calculation of the indicators.

In addition, the use of public and secondary data, i.e. patent data, permits to avoid also the ethics issues due to the use of artificial intelligence and machine learning approaches (Siau and Wang, 2020; Makarius et al., 2020). In fact, data security, privacy, transparency, autonomy, intentionality, responsibility, human and social rights challenges do not come up. Even if the IPI is based on results of machine learning analyses, privacy issues do not emerge 
$\mathrm{MD}$

59,13

\section{0}

because IPI do not use personal data. Transparency, autonomy, intentionality, and responsibility concerns do not arise because the IPI is easily interpretable and it is not used to take decision that are not under the control of managers. Finally, human and social rights are respected because the use of the IPI should not influence for example ethical standards but only provide managers a decision tool that permits to better decide firms' R\&D investments and enhance firms' innovation performance.

\subsection{Theoretical implications}

The study aims to contribute to the innovation performance measurement literature. In particular, it provides a step forward in the innovation stream of literature that seeks to measure R\&D performance using secondary data. Thus, it takes advantage of the use of secondary data opening up to several uses, measures and analyses that can be done with patents in order to measure the innovation performance. From a methodological standpoint, it shows the usefulness of applying machine learning approaches also in the innovation field for decision making purposes. Indeed, machine learning approaches and artificial intelligence are still barely used in innovation fields, in particular when trying to measure and forecast performance and take decisions out of these results. In addition, the IPI is an instrument that can be used not only at a firm level but also at a regional level. For this reason, it could be an instrument useful also in innovation macroeconomic and regional studies and it can provide a contribution in this stream of literature. Finally, the IPI shows also a new way to combine current and future data, thanks to highly accurate techniques of forecasting such as the machine learning ones.

\subsection{Practical implications}

For managers and those in business the IPI may provide several implications and suggestions. As mentioned above, IPI can be calculated at a firm level, providing an indication not only on the performance of the single project but more in general on the innovation area. In this way R\&D managers may take decisions on the full portfolio and not only "correct" the single project. In addition, the information included in the IPI provides a nuanced overview of R\&D, suggesting in which areas to invest promptly (Park and LiPuma, 2020). The dimensions allow for identifying the strengths and weaknesses of innovation performance in their companies. It makes possible to position the company with respect to competitors and suggests the dimensions/areas that should be improved by the managers in order to increase innovation performance. The fact of having a multiple perspective and indicators that refer to different firms' areas and skills may foster the culture of innovation and all the department could be involved to enhance the innovation process of the organization (Hanifah et al., 2019). This is even truer considering the usability and flexibility of the instrument. That flexibility may be of particular importance in terms of improving the responsiveness and achieving better performance (Kumar and Singh, 2019; Kindström et al., 2013).

For policy-makers, it is worth noting that IPI can be applied in different contexts, such as companies that belong to the same geographic area, to the same industrial sector, to the same technological area, with the same dimension, with the same governance, etc. This shows the high flexibility of the tool and gives policy-makers the possibility to quickly compare different sectors and territories and take decisions as a result (Kumar and Singh, 2019; Kindström et al., 2013). For financiers, the IPI may support their decision, suggesting which companies that perform better, and what their strengths and weaknesses are.

For patent experts, IPI provides some suggestions on how to write the patent. It indicates the most important features to look at in order to increase the number of forward citations and consequently the technology performance. 


\section{Conclusion, limitations and future research}

The paper has presented a new measure of Innovation Performance, called Innovation Patent Index (IPI) based on secondary data, i.e. the patent database. The IPI is defined by means of five indicators that represent the five most relevant dimensions, which are efficiency, time, diversification, quality and internationalization. These dimensions have been identified according to the literature (Lee et al., 2018) and applying three different machine learning algorithms, i.e. RLS, the DNNs and the DTs to the patent database.

The IPI has been applied to a territory and an industrial sector. Results have shown that IPI is an immediate tool of measurement. In fact, it is able to overcome the limits of measures based on primary data and, through an analysis of the indicators, it gives information about the reasons for a good or poor innovation performance. Compared to existing indicators, generally not widely used because of their complexity or their limited ability to predict, the IPI is a simple and at the same time forward-looking tool of innovation performance measurement (Lee et al., 2018). Moreover, IPI overcomes limits of other, widely used measures based on secondary data, such as, patent counts and forward citations (Park and Park, 2006; Aristodemou and Tietze, 2018). In fact, the number of patents does not seem to be fully representative of the innovation performance and the use of other indicators provides a better understanding of innovation performance. Concerning the forward citations, they are considered a better indicator than the patent counts (Hall et al., 2005), however, they can be known only after a long period of time (Brinn et al., 2003). The IPI, on the other hand, merges the patent count with forward citation predictors, i.e. the other patents' features already included in the patent when issued, overcoming the limitations of the other measures. In fact it enriches the number of patents measure and overcomes the time issues of the forward citation measure. IPI gives each firm or territory information not only about the level of IP (the rank) but also the IP profile that can be used by managers, businessmen, policymakers, organizations, patent experts and financiers to evaluate and plan future activities, to enhance the innovation performance and capability, to find financing and to support and improve innovation.

This work is not without limitations. Despite most of companies extensively apply for patents, in some sector they are not widely used. Thus, a specific innovation index could be developed for the sectors that do not largely apply for patents. In addition, the IPI is based only on the pure number of forward citations to have a forward looking perspective. In further studies, other patent features could be used, as for example forward citations indexes (Aristodemou and Tietze, 2018).

\section{Notes}

1. Likert Scale is a type of rating scale used to measure attitudes or opinions. With this scale, respondents are asked to rate items on a level of agreement. For example: Strongly agree, Agree, Neutral, Disagree, Strongly disagree.

2. https://ec.europa.eu/eurostat/web/microdata/community-innovation-survey.

3. www.questel.com.

4. Italian plastics and rubber processing machinery, ancillary equipment and moulds manufacturer's association.

5. www.questel.com.

6. www.amaplast.org.

\section{References}

Acs, Z.J., Anselin, L. and Varga, A. (2002), "Patents and innovation counts as measures of regional production of new knowledge", Research Policy, Vol. 31 No. 7, pp. 1069-1085.

A measure of innovation performance 
$\mathrm{MD}$

59,13

92

Altmann, A., Toloşi, L., Sander, O. and Lengauer, T. (2010), "Permutation importance: a corrected feature importance measure”, Bioinformatics, Vol. 26 No. 10, pp. 1340-1347.

Aristodemou, L. and Tietze, F. (2018), "Citations as a measure of technological impact: a review of forward citation-based measures", World Patent Information, Vol. 53, pp. 39-44.

Bahl, M., Lahiri, S. and Mukherjee, D. (2020), "Managing internationalization and innovation tradeoffs in entrepreneurial firms: evidence from transition economies", Journal of World Business, Vol. 56 No. 1, p. 101150.

Becheikh, N., Landry, R. and Amara, N. (2006), "Lessons from innovation empirical studies in the manufacturing sector: a systematic review of the literature from 1993-2003”, Technovation, Vol. 26 Nos 5-6, pp. 644-664.

Belderbos, R., Cassiman, B., Faems, D., Leten, B. and Van Looy, B. (2014), "Co-ownership of intellectual property: exploring the value-appropriation and value-creation implications of co-patenting with different partners", Research Policy, Vol. 43 No. 5, pp. 841-852.

Bessen, J. (2008), "The value of us patents by owner and patent characteristics", Research Policy, Vol. 37 No. 5 , pp. 932-945.

Brinn, M.W., Fleming, J.M., Hannaka, F.M., Thomas, C.B. and Beling, P.A. (2003), "Investigation of forward citation count as a patent analysis method", IEEE Systems and Information Engineering Design Symposium, IEEE, pp. 1-6, doi: 10.1109/SIEDS.2003.157996.

Burrus, R.T., Graham, J.E. and Jones, A.T. (2018), "Regional innovation and firm performance”, Journal of Business Research, Vol. 88, pp. 357-362.

Cainelli, G., Evangelista, R. and Savona, M. (2005), "Innovation and economic performance in services: a firm-level analysis", Cambridge Journal of Economics, Vol. 30 No. 3, pp. 435-458.

Carayannis, E.G. and Provance, M. (2008), "Measuring firm innovativeness: towards a composite innovation index built on firm innovative posture, propensity and performance attributes", International Journal of Innovation and Regional Development, Vol. 1 No. 1, pp. 90-107.

Chiesa, V., Frattini, F., Lazzarotti, V. and Manzini, R. (2008), "Designing a performance measurement system for the research activities: a reference framework and an empirical study", Journal of Engineering and Technology Management, Vol. 25 No. 3, pp. 213-226.

Choi, J. and Hwang, Y.-S. (2014), "Patent keyword network analysis for improving technology development efficiency", Technological Forecasting and Social Change, Vol. 83, pp. 170-182.

Cincotti, S., Gallo, G., Ponta, L. and Raberto, M. (2014), "Modeling and forecasting of electricity spotprices: computational intelligence vs classical econometrics", AI Communications, Vol. 27 No. 3, pp. 301-314.

Datta, A., Mukherjee, D. and Jessup, L. (2015), "Understanding commercialization of technological innovation: taking stock and moving forward”, R\&D Management, Vol. 45 No. 3, pp. 215-249.

De Jong, J.P. and Vermeulen, P.A. (2006), "Determinants of product innovation in small firms: a comparison across industries”, International Small Business Journal, Vol. 24 No. 6, pp. 587-609.

De Rassenfosse, G., Dernis, H., Guellec, D., Picci, L. and de la Potterie, B.V.P. (2013), "The worldwide count of priority patents: a new indicator of inventive activity", Research Policy, Vol. 42 No. 3, pp. 720-737.

Dechezleprêtre, A. and Martin, R. (2010), "Low carbon innovation in the UK: evidence from patent data", in Report for the UK Committee on Climate Change, Centre for Climate Change Economics and Policy, Grantham Research Institute on Climate Change and the Environment, Vol. 4.

Dechezleprêtre, A., Ménière, Y. and Mohnen, M. (2017), "International patent families: from application strategies to statistical indicators", Scientometrics, Vol. 111 No. 2, pp. 793-828.

Dewangan, V. and Godse, M. (2014), "Towards a holistic enterprise innovation performance measurement system", Technovation, Vol. 34 No. 9, pp. 536-545. 
Dziallas, M. and Blind, K. (2019), "Innovation indicators throughout the innovation process: an extensive literature analysis", Technovation, Vol. 80, pp. 3-29.

Encaoua, D., Guellec, D. and Martínez, C. (2006), "Patent systems for encouraging innovation: lessons from economic analysis", Research Policy, Vol. 35 No. 9, pp. 1423-1440.

Garg, K. and Padhi, P. (1998), "Scientometric study of laser patent literature", Scientometrics, Vol. 43 No. 3, pp. 443-454.

Gaur, A.S., Ma, H. and Ge, B. (2019), "MNC strategy, knowledge transfer context, and knowledge flow in MNEs", Journal of Knowledge Management, Vol. 23 No. 9, pp. 1885-1900.

Govindarajan, V. and Govindarajan, S. (1993), Strategic Cost Management: The New Tool for Competitive Advantage, Simon and Schuster, New York, NY.

Griliches, Z. (1990), "Patent statistics as economic indicators: a survey", Journal of Economic Literature, Vol. 28 No. 4, pp. 1661-1707.

Guyon, I. and Elisseeff, A. (2003), "An introduction to variable and feature selection", Journal of Machine Learning Research, Vol. 3, pp. 1157-1182.

Hagedoorn, J. and Cloodt, M. (2003), "Measuring innovative performance: is there an advantage in using multiple indicators?”, Research Policy, Vol. 32 No. 8, pp. 1365-1379.

Hall, B.H., Jaffe, A. and Trajtenberg, M. (2005), "Market value and patent citations", The RAND Journal of Economics, Vol. 36 No. 1, pp. 16-38.

Hall, B.H., Thoma, G. and Torrisi, S. (2007), "The market value of patents and R\&D: evidence from European firms", Academy of Management Proceedings, Academy of Management Briarcliff Manor, New York, Vol. 2007, pp. 1-6.

Hanifah, H., Halim, H.A., Ahmad, N.H. and Vafaei-Zadeh, A. (2019), "Emanating the key factors of innovation performance: leveraging on the innovation culture among SMEs in Malaysia", Journal of Asia Business Studies, Vol. 13 No. 4, pp. 559-587.

Harhoff, D., Scherer, F.M. and Vopel, K. (2003), "Citations, family size, opposition and the value of patent rights", Research Policy, Vol. 32 No. 8, pp. 1343-1363.

Hou, B., Hong, J. and Zhu, R. (2019), "Exploration/exploitation innovation and firm performance: the mediation of entrepreneurial orientation and moderation of competitive intensity", Journal of Asia Business Studies, Vol. 13 No. 4, pp. 489-506.

Jaffe, A.B. and Palmer, K. (1997), "Environmental regulation and innovation: a panel data study", The Review of Economics and Statistics, Vol. 79 No. 4, pp. 610-619.

Janssen, S., Moeller, K. and Schlaefke, M. (2011), "Using performance measures conceptually in innovation control”, Journal of Management Control, Vol. 22 No. 1, p. 107.

Kerssens-van Drongelen, I.c. and Bilderbeek, J. (1999), "R\&d performance measurement: more than choosing a set of metrics", R\&D Management, Vol. 29 No. 1, pp. 35-46.

Kindström, D., Kowalkowski, C. and Sandberg, E. (2013), "Enabling service innovation: a dynamic capabilities approach", Journal of Business Research, Vol. 66 No. 8, pp. 1063-1073.

Kitsios, F. and Kamariotou, M. (2016), "The impact of information technology and the alignment between business and service innovation strategy on service innovation performance", 2016 International Conference on Industrial Engineering, Management Science and Application (ICIMSA), IEEE, pp. 1-5, doi: 10.1109/ICIMSA.2016.7504042.

Kumar, P. and Singh, A.P. (2019), "Flexibility in service operations: review, synthesis and research agenda", Benchmarking: An International Journal, Vol. 27 No. 7, pp. 2108-2129.

Lanjouw, J.O. and Schankerman, M. (2004), "Patent quality and research productivity: measuring innovation with multiple indicators", The Economic Journal, Vol. 114 No. 495, pp. 441-465.

Lazzarotti, V., Manzini, R. and Mari, L. (2011), "A model for R\&D performance measurement", International Journal of Production Economics, Vol. 134 No. 1, pp. 212-223.

A measure of innovation performance 
$\mathrm{MD}$

59,13

Lee, C., Kwon, O., Kim, M. and Kwon, D. (2018), "Early identification of emerging technologies: a machine learning approach using multiple patent indicators", Technological Forecasting and Social Change, Vol. 127, pp. 291-303.

Liu, J., Chen, J. and Tao, Y. (2015), "Innovation performance in new product development teams in China's technology ventures: the role of behavioral integration dimensions and collective efficacy”, Journal of Product Innovation Management, Vol. 32 No. 1, pp. 29-44.

Love, J.H. and Roper, S. (2015), "SME innovation, exporting and growth: a review of existing evidence”, International Small Business Journal, Vol. 33 No. 1, pp. 28-48.

Lulli, A., Oneto, L. and Anguita, D. (2018), "Mining big data with random forests", Cognitive Computation, Vol. 11, pp. 294-316.

Mahnken, T.A. and Moehrle, M.G. (2018), "Multi-cross-industry innovation patents in the USA-A combination of PATSTAT and Orbis search", World Patent Information, Vol. 55, pp. 52-60.

Makarius, E.E., Mukherjee, D., Fox, J.D. and Fox, A.K. (2020), "Rising with the machines: a sociotechnical framework for bringing artificial intelligence into the organization", Journal of Business Research, Vol. 120, pp. 262-273.

Moaniba, I.M., Su, H.-N. and Lee, P.-C. (2018), "Knowledge recombination and technological innovation: the important role of cross-disciplinary knowledge", Innovation, Vol. 20 No. 4, pp. 326-352.

Mueller, H. (2015), "Biotech patent landscapes: a reflection of global innovation?", Pharmaceutical Patent Analyst, Vol. 4 No. 5, pp. 349-350.

Nagaoka, S., Motohashi, K. and Goto, A. (2010), "Patent statistics as an innovation indicator", in Handbook of the Economics of Innovation, Vol. 2, pp. 1083-1127.

Narin, F., Carpenter, M.P. and Woolf, P. (1984), "Technological performance assessments based on patents and patent citations", IEEE Transactions on Engineering Management, Vol. 4, pp. 172-183.

Nuruzzaman, N., Gaur, A.S. and Sambharya, R.B. (2019), "A microfoundations approach to studying innovation in multinational subsidiaries", Global Strategy Journal, Vol. 9 No. 1, pp. 92-116.

Ojanen, V. and Vuola, O. (2006), "Coping with the multiple dimensions of R\&D performance analysis”, International Journal of Technology Management, Vol. 33 Nos 2-3, pp. 279-290.

Pakes, A. and Griliches, Z. (1980), "Patents and R\&D at the firm level: a first Report", Economics Letter No. 5, pp. 377-381.

Papageorgiadis, N. and Sofka, W. (2020), "Patent enforcement across 51 countries-patent enforcement index 1998-2017", Journal of World Business, Vol. 55 No. 4, p. 101092.

Park, S. and LiPuma, J.A. (2020), "New venture internationalization: the role of venture capital types and reputation", Journal of World Business, Vol. 55 No. 1, p. 101025.

Park, G. and Park, Y. (2006), "On the measurement of patent stock as knowledge indicators", Technological Forecasting and Social Change, Vol. 73 No. 7, pp. 793-812.

Ponta, L., Puliga, G., Oneto, L. and Manzini, R. (2020a), "Innovation capability of firms: a big data approach with patents", in Oneto, L., Navarin, N., Sperduti, A. and Anguita, D. (Eds), Recent Advances in Big Data and Deep Learning, Springer International Publishing, Cham, pp. 169-179.

Ponta, L., Puliga, G., Oneto, L. and Manzini, R. (2020b), "Identifying the determinants of innovation capability with machine learning and patents", IEEE Management Engineering, In press.

Reitzig, M. (2004), "Improving patent valuations for management purposes-validating new indicators by analyzing application rationales", Research Policy, Vol. 33 Nos 6-7, pp. 939-957.

Saunila, M. (2016), "Performance measurement approach for innovation capability in SMEs", International Journal of Productivity and Performance Management, Vol. 65 No. 2, pp. 162-176.

Scalera, V.G., Mukherjee, D., Perri, A. and Mudambi, R. (2014), "A longitudinal study of MNE innovation: the case of Goodyear", Multinational Business Review. 
Scherer, F.M. (1965), "Firm size, market structure, opportunity, and the output of patented inventions", The American Economic Review, Vol. 55 No. 5, pp. 1097-1125.

Scherer, M. (1992), "Research on patents and the economy: the state of the art", Contribution to the 1st EPO-IFO Workshop, Results and Methods of Economic Patent Research with Respect to the European System, Munich.

Schumann, P.A. Jr, Ransley, D.L. and Prestwood, D.C. (1995), "Measuring R\&D performance", Research-Technology Management, Vol. 38 No. 3, pp. 45-54.

Shalev-Shwartz, S. and Ben-David, S. (2014), Understanding Machine Learning: From Theory to Algorithms, Cambridge University Press, New York.

Siau, K. and Wang, W. (2020), “Artificial intelligence (AI) ethics: ethics of AI and ethical AI”, Journal of Database Management, Vol. 31 No. 2, pp. 74-87.

Soosay, C.A. and Chapman, R.L. (2006), "An empirical examination of performance measurement for managing continuous innovation in logistics", Knowledge and Process Management, Vol. 13 No. 3, pp. 192-205.

Svensson, R. (2015), "Measuring innovation using patent data”, Technical report, IFN Working Paper, Stockholm.

Tkáč, M. and Verner, R. (2016), “Artificial neural networks in business: two decades of research", Applied Soft Computing, Vol. 38, pp. 788-804.

Tohumcu, Z. and Karasakal, E. (2010), "R\&d project performance evaluation with multiple and interdependent criteria”, IEEE Transactions on Engineering Management, Vol. 57 No. 4, pp. 620-633.

Tu, J.V. (1996), "Advantages and disadvantages of using artificial neural networks versus logistic regression for predicting medical outcomes", Journal of Clinical Epidemiology, Vol. 49 No. 11, pp. $1225-1231$.

Walsh, V. (1994), "Technology and the economy - the key relationships", (Organisation for economic co-operation and development, Paris, (1992) pp. 328, 260 FF', Research Policy, Vol. 23 No. 4, pp. $473-475$.

\section{A measure of innovation performance}


MD

59,13

96

\section{Appendix}

Results for all Lombardy provinces

This appendix shows all the figure for the provinces of the Lombardy region. Figure A1 shows the IPI dimensions in the period after crisis for the provinces not shown in the paper, i.e. Bergamo, Brescia, Monza Brianza, Como, Pavia, Mantova, Cremona, Lecco and Sondrio. Figure A2 shows, year by year, the five dimensions of IPI for the provinces not shown in the paper, i.e. Bergamo, Brescia, Monza Brianza, Como, Pavia, Mantova, Cremona, Lecco and Sondrio. Figure A3 shows the IPI's dimensions of the provinces not shown in the paper, i.e. Bergamo, Brescia, Monza Brianza, Como, Pavia, Mantova, Cremona, Lecco and Sondrio evaluated in different time ranges.

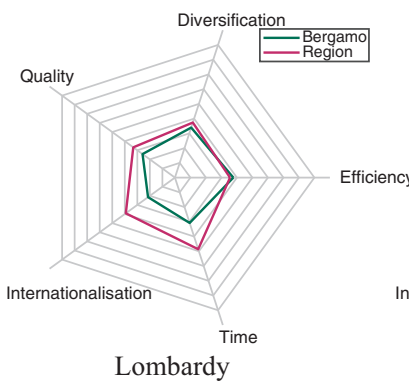

(a)

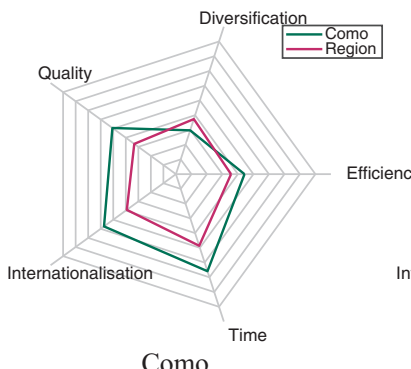

(d)

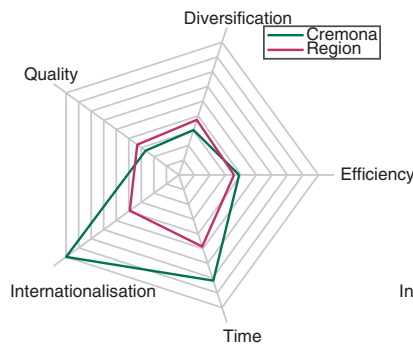

Cremona

(g)

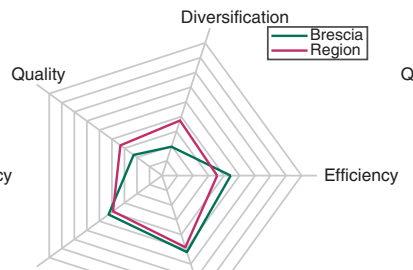

Internationalisation Time

Brescia

(b)

Diversification

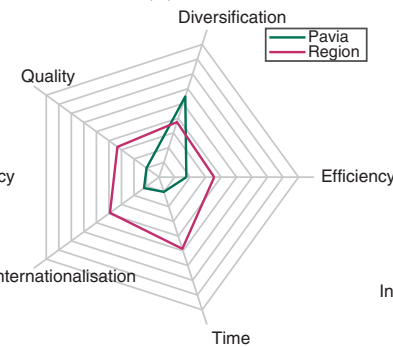

Pavia

(e)

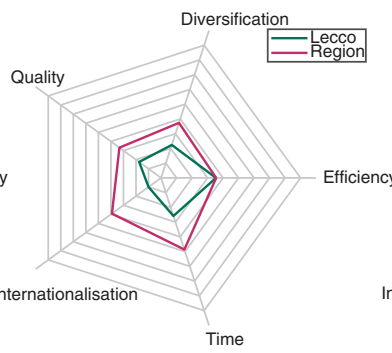

Lecco

(h)

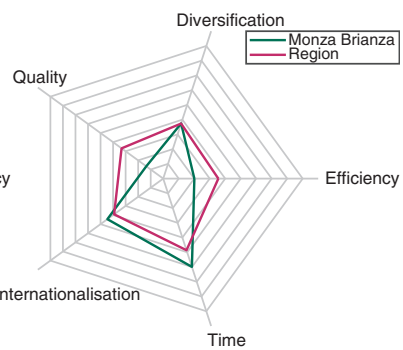

Monza Brianza

(c)

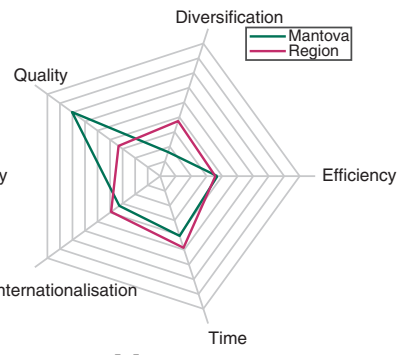

Mantova

(f)

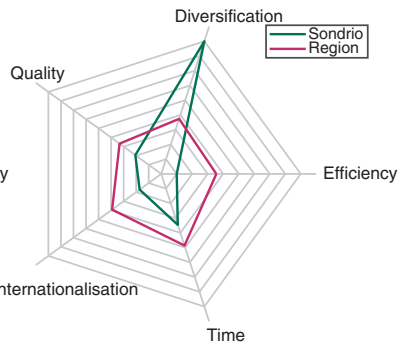

Sondrio

(i) 


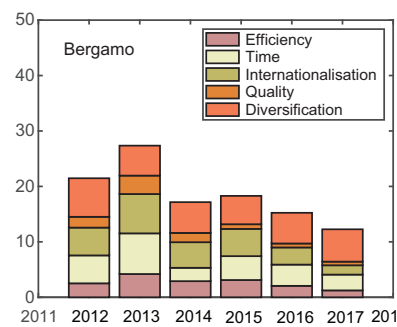

2011201220132014201520162017201820112012201320142015201620172018 years

\section{Bergamo}

(a)

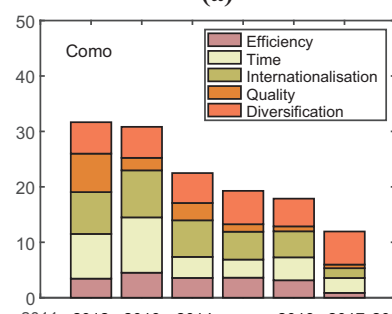

201120122013201420152016201720182011201220132014 years

Com

(d)

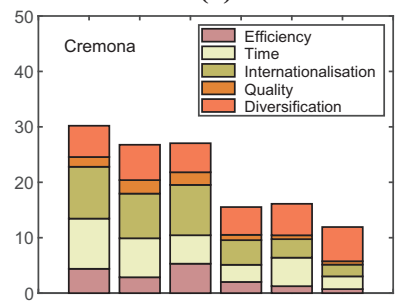

20112012201320142015201620172018 years

\section{Cremona}

(g)

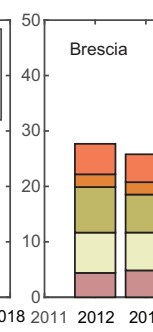

years

Brescia

(b)

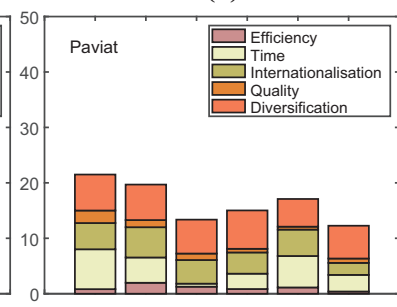
years

(e)

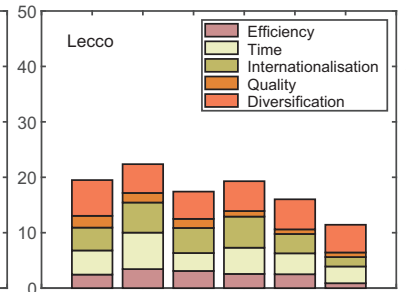

Tfici

alisation

$14 \quad 2015$
years

Lecco

(h)

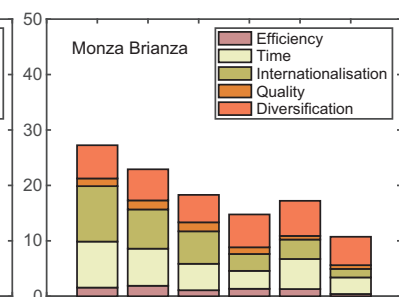

20142015201620172018 years

Monza Brianza

(c)

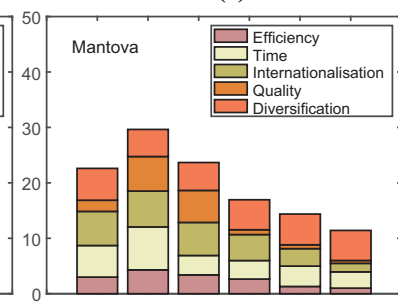

142015201620172018

Mantova

(f)

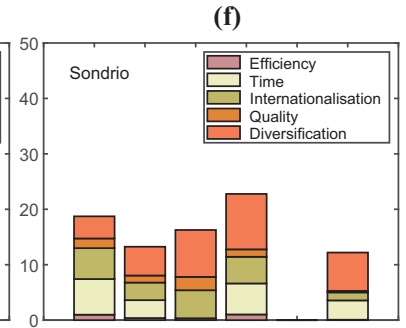

years

Sondrio

(i)
A measure of innovation performance

Figure A2.

IPI dimensions in the period after crisis year by year 
$\mathrm{MD}$

59,13

98

Figure A3.

IPI dimensions in the three periods for each province not reported in the paper

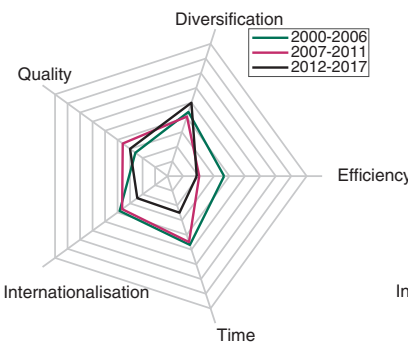

Bergamo

(a)

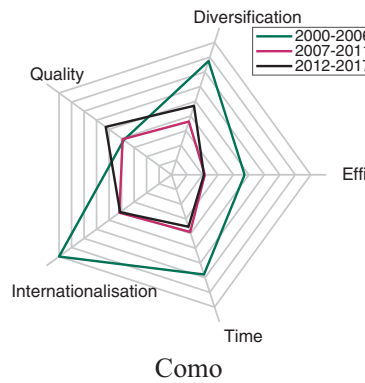

(d)

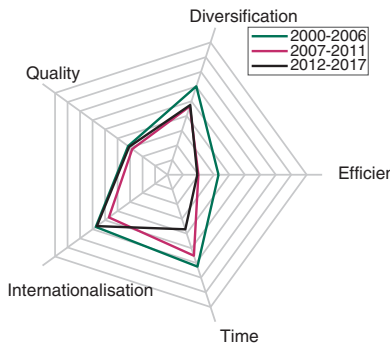

Cremona

(g)

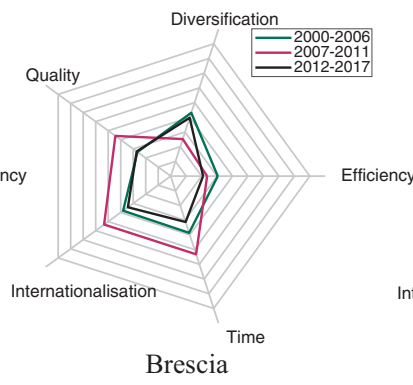

(b)

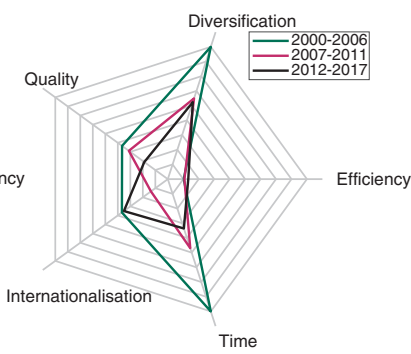

Monza Brianza

(c)

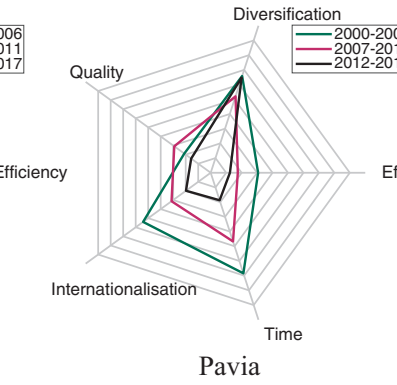

(e)

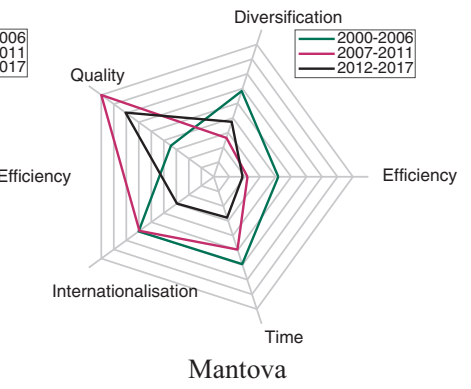

(f)

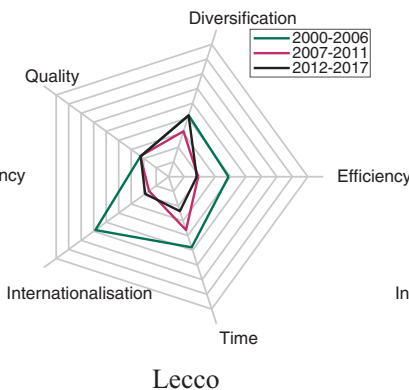

(h)

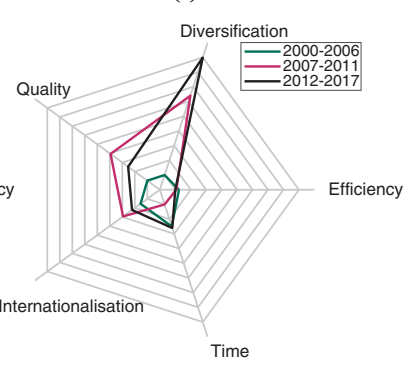

Sondrio

\section{Corresponding author}

Linda Ponta can be contacted at:1ponta@liuc.it

For instructions on how to order reprints of this article, please visit our website:

www.emeraldgrouppublishing.com/licensing/reprints.htm

Or contact us for further details: permissions@emeraldinsight.com 